\title{
Urinary Catecholamines and Mitral Valve Prolapse in Panic-Anxiety Patients
}

\author{
Randolph M. Nesse, Oliver G. Cameron, Andrew J. Buda, Daisy S. McCann, \\ George C. Curtis, and Marla J. Huber-Smith
}

Received June 12, 1984; revised version received October 22, 1984; accepted December 11, 1984.

\begin{abstract}
Free norepinephrine and epinephrine were measured in two consecutive 12-hour urine collections gathered during normal activity and sleep from 23 panic-anxiety patients and 9 normal subjects. Mitral value prolapse (MVP) was found in 7 of 20 patients who had echocardiograms. Mean nighttime norepinephrine and epinephrine excretion in panic-anxiety patients without MVP was significantly higher than that of control subjects, and was significantly higher than that of anxiety patients with MVP. In the daytime, all groups had higher catecholamine (CA) levels, but the differences between the groups were less pronounced. Medication significantly relieved symptoms and was associated with decreased CA levels. Elevated basal CA levels may characterize the subgroup of panic-anxiety patients who do not have MVP.
\end{abstract}

Key Words. Panic, anxiety, mitral valve prolapse, urine, epinephrine, norepinephrine, humans.

Urinary and plasma catecholamine (CA) elevations in normal subjects during stress and anxiety have been well documented (Cannon, 1915; Frankenhauser, 1971; Lader, 1974; Redmond, 1979; Usdin et al., 1980; Ward et al., 1983; Nesse et al., in press). There have, however, been relatively few studies of CA levels in patients with anxiety disorders (Lader, 1978). This paucity of studies is surprising in view of the likelihood that CAs are mediators of anxiety symptoms, and the possibility that elevated CAs characterize some anxicty disorders.

Several studies report correlations between CA levels and anxiety in patients with depression. In 13 drug-free patients with depression, elevated plasma CA levels were strongly correlated with anxiety ratings $(r=0.69, p<0.01)$, but were weakly correlated with depression ratings $(r=0.261)$ (Wyatt et al., 1971). In another study of patients with anxiety and depression, red blood cell (RBC) catechol- $O$-methyltransferase (COMT) levels were above the normal range only in the patients who had mainly anxiety symptoms (Shulman et al., 1978).

Randolph M. Nesse, M.D., is Assistant Professor, Oliver G. Cameron. M.D., Ph.D., is Assistant Professor, and George C. Curtis. M.D., is Professor. Department of Psychiatry, University of Michigan Medical Center. Andrew J. Buda, M.D., is Assistant Professor, and Daisy S. McCann, Ph.D., is Associate Professor of Biological Chemistry, Department of Internal Medicine, University of Michigan. Marla Huber-Smith, B.A., is Research Associate, Wayne County General Hospital, Westland, MI. (Reprint requests to Dr. R.M. Nesse. Dept. of Psychiatry, University of Michigan Medical Center, Box 56, Ann Arbor, M I 48109 , USA.)

0165-1781/85/\$03.30 1985 Elsevier Science Publishers B.V. (Biomedical Division) 
Patients with generalized anxiety disorder have been reported to have plasma epinephrine and norepinephrine levels significantly higher than controls, but their RBC COMT levels were only slightly above those of controls (Mathew et al., 1980). The same group of researchers subsequently failed to confirm elevations of plasma $\mathrm{CA}$ in generalized anxiety patients, and suggested that the earlier work might have been in error because blood samples were drawn immediately following venipuncture (Mathew et al., 1982). Perhaps patients with generalized anxiety disorder have a greater $\mathrm{CA}$ response to venipuncture than do normals. Increased plasma 3-methoxy4-hydroxyphenethyleneglycol (MHPG) has been significantly correlated with anxiety ratings in normals (Uhde et al., 1982), and in phobic-anxious patients (Ko et al., 1983), but comparisons of plasma MHPG levels in anxiety disorder patients and normals are not available. There is a trend for urinary $\mathrm{MHPG}$ excretion to be higher in patients with panic attacks when compared to normal controls (Sheehan et al., 1984).

Patients with panic disorder have been reported to have elevated plasma levels of both epinephrine and norepinephrine (Nesse et al., 1984; Cameron et al., 1984), or of epinephrine only (Appleby et al., 1981). Patients who had a panic attack during a lactate infusion tended to have higher plasma epinephrine levels than other patients, after the infusion (Appleby et al., 1981). In that study, pre-infusion epinephrine levels were reported to be equivalent in patients who did, and did not, develop panic attacks. A more recent report from the same group states that elevated baseline epinephrine was "the only variable that distinguished patients who went on to panic from those who did not" (Liebowitz et al., 1983). Ballenger et al. (1984) have reported significant elevations of plasma epinephrine and norepinephrine in 36 patients with agoraphobia as compared to 9 normal controls. The differences were more pronounced when subjects were lying than standing. The patients' mean level of plasma norepinephrine was three times higher than that of the normals while lying down (Ballenger et al., 1984).

Patients with panic disorder have an increased prevalence of mitral valve prolapse (MVP) (Crowe et al., 1980). People with MVP have anxiety-like symptoms, elevated plasma CA levels (Boudoulas et al., 1980; DeCarvalho et al., 1979; Pasternac et al., 1982; Gaffney et al., 1983), and elevated urinary CA excretion (Boudoulas et al., 1983). The present report considers the hypothesis that the elevated CA levels reported for panic patients are an indirect result of the increased prevalence of MVP in panic patients. Separate measurement of daytime and nighttime CA excretion rates also allows consideration of the possibility that group differences in $\mathrm{CA}$ excretion result from different daytime activity levels.

\section{Methods}

Subjects. Twenty-three patients with panic disorder or agoraphohia with panic attacks were compared to nine control subjects (see Table 1). The patients had requested treatment at the University of Michigan Anxiety Disorders Clinic. Diagnoses were made according to $D S M-I I I$ criteria (American Psychiatric Association, 1980) after a clinical examination by a psychiatrist experienced in diagnosing anxiety disorders. The controls were recruited by newspaper advertisements. Their psychiatric examinations revealed no anxiety or other mental disorder. All subjects were physically healthy and were not taking medication. All but two subjects had been medication free for a month or more. One patient had taken $4 \mathrm{mg}$ of diazepam and 4 ing of 
trifluroperazine/day, and another had taken $15 \mathrm{mg}$ of diazepam and $40 \mathrm{mg}$ of naldolol/day, until 2 weeks before the study.

Table 1. Subjects

\begin{tabular}{|c|c|c|c|c|c|}
\hline & Normal & $\begin{array}{l}\text { All } \\
\text { PD }\end{array}$ & $\begin{array}{c}\text { PD } \\
\text { w/MVP1 }\end{array}$ & $\begin{array}{c}\text { PD } \\
\text { w/o MVP1 }\end{array}$ & $\begin{array}{c}\text { PD } \\
\text { w/o ECHO1 }\end{array}$ \\
\hline$n($ total $=32)$ & 9 & 23 & 7 & 13 & 3 \\
\hline $\operatorname{Sex}(M / F)$ & $7 / 2$ & $5 / 18$ & $1 / 6$ & $3 / 10$ & $1 / 2$ \\
\hline $\begin{array}{c}\text { Mean age } \\
\quad \text { (years) }\end{array}$ & $26.0(5.2)$ & $32.0(11.3)$ & $35.6(14.2)$ & $29.1(8.6)$ & $3.60(14.7)$ \\
\hline $\begin{array}{l}\text { Mean age at } \\
\text { onset (years) }\end{array}$ & - & $22.2(10.9)$ & $24.4(14.2)$ & $22.1(9.5)$ & $17.3(10.2)$ \\
\hline $\begin{array}{l}\text { Mean duration } \\
\text { of illness } \\
\text { (years) }\end{array}$ & - & $9.78(9.68)$ & $11.14(9.72)$ & $7.00(7.15)$ & $18.67(16.26)$ \\
\hline $\begin{array}{l}\text { Mean weight } \\
(\mathrm{kg})\end{array}$ & $76.0(12.7)$ & $64.6(11.0)$ & $60.7(8.4)$ & $64.9(12.6)$ & $72.7(12.4)$ \\
\hline $\begin{array}{l}\text { Mean height } \\
(\mathrm{cm})\end{array}$ & $1 / 6.3(8.5)$ & $165.9(8.4)$ & $163.6(11.2)$ & $166.3(6.1)$ & $169.3(10.6)$ \\
\hline
\end{tabular}

$\mathrm{PD}=$ panic disorder; $\mathrm{PD} \mathrm{w} / \mathrm{MVP}=$ panic disorder with mitral valve prolapse; $\mathrm{PD} \mathrm{w} / \mathrm{o} \mathrm{MVP}=$ panic disorder without mitral valve prolapse; $\mathrm{PD}$ w/O $\mathrm{ECHO}=$ panic disorder without echocardiogram; standard deviations given in parentheses.

1. Subgroups of the All PD group.

Urine Collections. Subjects received verbal and written instructions regarding the urine collection technique and schedule. They were instructed to follow their usual diet but to avoid all strenuous exercise, medication, and caffeinated and alcoholic beverages during the urine collection. I wo consecutive 12 -hour samples ( 7 a.m. -7 p.m.; 7 p.m.-7 a.m.) were collected in jugs containing $10 \mathrm{ml}$ of $5 \%$ acetic acid. Within 24 hours of collection, urine samples were brought to the laboratory, where total volume was recorded and samples were labeled and frozen at $-20^{\circ} \mathrm{C}$. After 3-14 months of treatment with imipramine, alprazolam, or a $\beta$-blocker, 10 patients collected urine a second time according to the same protocol. Urine samples were excluded if total volume was less than $300 \mathrm{ml} / 12$ hours or if creatinine content was less than $0.3 \mathrm{mg} / 12$ hours.

Assay. Epinephrine and norepinephrine were assayed by our modification of a single isotope derivative radioenzymatic technique (McCann and Huber-Smith, 1984). This assay has an intra-assay coefficient of variation of $3.92 \%$, and an inter-assay coefficient of variation of $10.7 \%$.

Mitral Valve Prolapse Evaluation. Twenty of the patients and three of the controls had a phonocardiogram, auscultation by a cardiologist, and two-dimensional and M-mode echocardiograms, to determine if MVP was present. The MVP evaluations were assessed independently by three cardiologists who were blind to the clinical diagnosis, and MVP was considered present only if at least two of the cardiologists agreed on that diagnosis, based on M-mode or two-dimensional echocardiographic data that were interpreted using standard criteria. On M-mode echocardiography, MVP was considered present if mid-systolic buckling or systolic hammocking of $2 \mathrm{~mm}$ posterior to the C-D point was observed (Markiewicz et al., 1976). On two-dimensional echocardiogram, MVP was defined by specific criteria for the parasternal long-axis view (Gilbert et al., 1976) and for the apical four-chamber view (Morganroth et al., 1980). 
SCL-90. Subjects completed the Symptom Checklist 90-R (SCL-90) at the initial evaluation and again at the second urine collection.

Data Analysis. Epinephrine and norepinephrine data were analyzed separately at each time of day. Analyses of variance (ANOVAs) with planned contrasts were used to compare the groups.

\section{Results}

Seven of the 20 patients who received echocardiograms (35\%) had MVP. Of three control subjects who had echocardiograms, none had MVP. Estimates of the prevalence of MVP using the same criteria for women in the general population are in the range of $6 \%$ to $21 \%$ (Markiewicz et al., 1976; Rosenberg et al., 1983).

Patients excreted more of each CA during daytime and at night, but the difference was significant only for nighttime norepinephrine $(p<0.036)$. The 13 patients who did not have MVP excreted substantially more CA than either patients with MVP or normal controls (see Fig. 1 and Table 2). These differences were much more prominent

\section{Fig. 1. Urinary tree norepinephrine and epinephrine}

DAYTIME NOREPINEPHRINE $(\mu \mathrm{g} / 12 \mathrm{~h})$

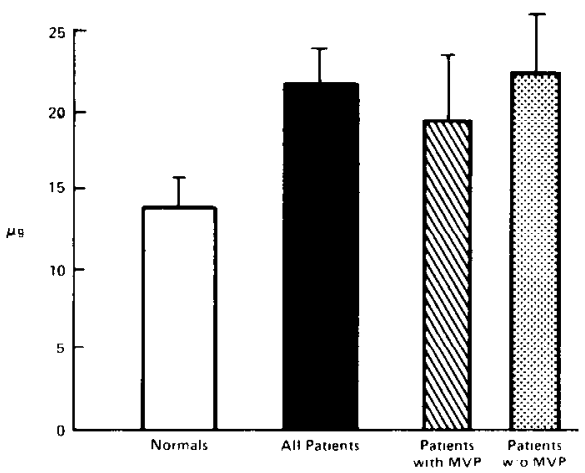

DAYTIME EPINEPHRINE $(\mu \mathrm{g} / 12 \mathrm{~h})$

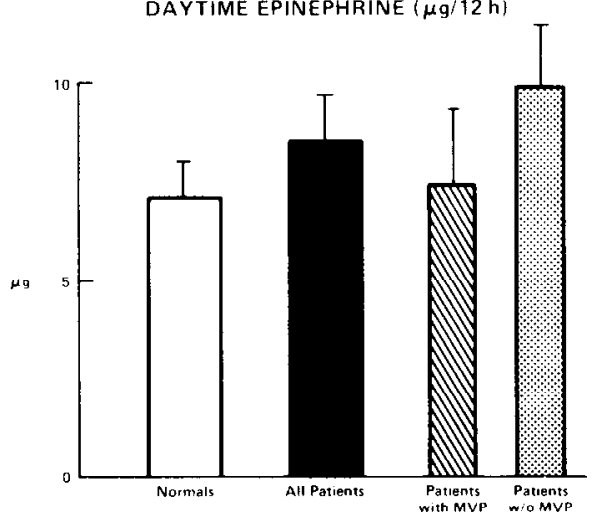

DIAGNOSTIC GROUP
NIGHTTIME NOREPINEPHRINE $(\mu \mathrm{g} / 12 \mathrm{~h}$

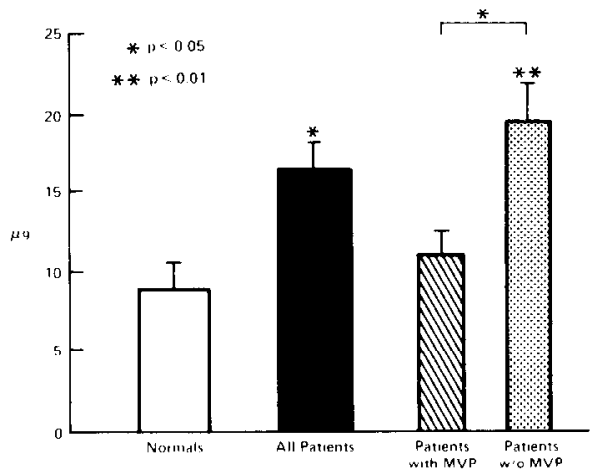

NIGHT TIME EPINEPHRINE $(\mu \mathrm{g} / 12 \mathrm{~h})$

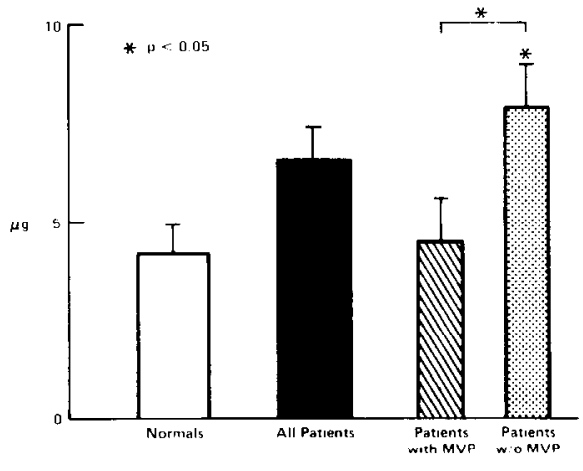

DIAGNOSTIC GROUP

Significance levels refer to comparisons with normals, unless otherwise indicated 
Table 2. Mean (SD) urinary norepinephrine ( $\mu \mathrm{g} / 12$ hours)

\begin{tabular}{lrcc}
\hline & $n$ & Day & Night \\
\hline All PD & 22 & $21.48(11.43)$ & $16.38(7.86)$ \\
PD w/MVP & 7 & $19.28(11.14)$ & $10.94(4.22)$ \\
PD w/o MVP & 12 & $22.35(12.90)$ & $19.48(8.49)$ \\
All normals & 9 & $13.84(6.19)$ & $8.96(5.12)$ \\
& & & $F=4.89, p<0.036$ \\
All PD vs. all normals & & $F=3.12, \rho<0.088$ & $F=0.33$ \\
PD w/MVP vs. normals & & $F=1.05$ & $F=12.27, p<0.002$ \\
PD w/o MVP vs. normals & & $F=0.36, p<0.078$ & $F=7.43, p<0.011$ \\
PD w/MVP vs. PD w/o MVP & &
\end{tabular}

Mean (SD) urinary epinephrine ( $\mu \mathrm{g} / 12$ hours)

\begin{tabular}{lrcc}
\hline & $n$ & Day & Night \\
\hline All PD & 22 & $8.54(5.32)$ & $6.52(3.81)$ \\
PD w/MVP & 7 & $7.43(5.10)$ & $4.47(3.00)$ \\
PD w/o MVP & 12 & $9.85(5.80)$ & $7.88(4.03)$ \\
All normals & 9 & $7.09(2.80)$ & $4.14(2.35)$ \\
& & $F=0.10$ & $F=1.53$ \\
All PD vs. all normals & & $F=0.02$ & $F=0.03$ \\
PD w/MVP vs. normals & & $F=1.75$ & $F=6.20, p<0.019$ \\
PD w/o MVP vs. normals & & $F=1.16$ & $F=4.75, p<0.038$ \\
PD w/MVP vs. PD w/o MVP & &
\end{tabular}

See note to Table 1 for abbreviations

at night. Patients without MVP had nighttime epinephrine excretion significantly greater than both controls $(F=6.19, p<0.019)$ and patients with $\operatorname{MVP}(F=4.75, p<$ 0.038). Patients without MVP had nighttime norepinephrine excretion that was significantly higher than both controls $(F=12.27, p<0.002)$ and patients with MVP $(F=7.43, p<0.011)$. In the daytime, the differences between patients with and without MVP were minimal, while the differences persisted between controls and patients without MVP.

Nonparametric presentation of these data shows the consistency of the differences. For nighttime epinephrine, 18 of 23 patients $(78 \%)$ had values greater than the median for controls, and $11(48 \%)$ had values greater than the maximum for controls. Eleven of the 13 patients without MVP $(85 \%)$ had values greater than the median for patients with MVP. For nighttime norepinephrine, 21 of 23 patients ( $91 \%)$ had levels greater than the median for controls, and 8 of $23(35 \%)$ had levels greater than the maximum for controls. Ten of the 13 patients without MVP (77\%) had levels greater than the median for patients with MVP.

A two-way ANOVA was performed to consider the effect of time of day and its possible interaction with diagnosis. Norepinephrine excretion and epinephrine excretion were both significantly lower at night $(F=10.04, p<0.004$ and $F=8.38$, $p<0.008$, respectively), but there were no significant interactions between time of day and diagnosis. 
After 3-14 months of medication, SCL-90 subscale scores had significantly decreased (see Table 3). Urinary free epincphrinc and norepinephrine decreased after treatment, but the difference approached statistical significance only for nighttime norepinephrine excretion $(F=2.24, p<0.056)$. CA levels decreased more during treatment for those patients without MVP than for those with MVP, but the small number of subjects precludes more formal comparison.

The data were also analyzed with a two-way ANOVA (diagnosis by sex) with three covariates (age, weight, and height) and planned contrasts in order to consider the possibility that the results might be accounted for by group differences in sex, age, weight, or height. The effects of sex, of the sex by diagnosis interaction, and of the covariates were all insignificant $(p<0.10)$, and significant differences found in the main analysis remained significant in this analysis. Although the difference is not statistically significant, it is of interest that paticnts without MVP, when compared to those with MVP, had an earlier age of onset ( 22.1 vs. 24.4 years) and a shorter duration of illness before seeking treatment ( 7.00 vs. 11.14 years), possibly reflecting greater severity of illness. At the time of evaluation, however, patients with MVP had higher SCL-90 anxiety scores than patients without MVP (3.1 vs. 2.6; $t=1.36, p<0.19$ ).

Table 3. Mean values: Pretreatment vs. during treatment

\begin{tabular}{lcccc}
\hline & Pretreatment & $\begin{array}{c}\text { During } \\
\text { treatment }\end{array}$ & $\boldsymbol{t}$ & $\boldsymbol{p}$ \\
\hline Daytime epinephrine $(n=10)$ & 8.05 & 7.24 & 1.23 & NS \\
Nighttime epinephrine $(n=9)$ & 5.52 & 4.40 & 1.50 & NS \\
Daytime norepinephrine $(n=10)$ & 21.36 & 20.54 & 0.12 & NS \\
Nighttime norepinephrine $(n=9)$ & 15.54 & 10.59 & 2.24 & 0.056 \\
SCL anxiety $(n=8)$ & 3.10 & 1.52 & 3.20 & 0.015 \\
SCL somatic $(n=8)$ & 2.10 & 1.37 & 3.15 & 0.016 \\
SCL phobic $(n=8)$ & 2.60 & 1.53 & 2.76 & 0.028 \\
SCL obsessive-compulsive $(n=8)$ & 1.75 & 1.02 & 2.66 & 0.033 \\
SCL depression $(n=8)$ & 2.35 & 1.27 & 2.97 & 0.021 \\
\hline
\end{tabular}

\section{Discussion}

This study supports the increased prevalence of MVP reported for patients with panic anxiety, and it confirms prior reports of elevated $\mathrm{CA}$ levels in patients with panic disorder. Panic patients with MVP have free CA excretion rates generally similar to those of controls, while panic patients without MVP have CA excretion rates significantly greater than either normals or panic patients with MVP. These unexpected group differences were more pronounced for norepinephrine than epinephrine. The present findings differ from some plasma studies in which epinephrine differences predominated, but are consistent with the other plasma studies (Ballenger et al., 1984). Urine studies of CA metabolites would augment the free $C A$ results reported here.

These results differ from prior reports of elevated plasma CAs in subjects who have MVP. The discrepancy could result from differences between urinary and plasma 
CAs, or from differences between MVP subjects who do and do not have panic. It may be, however, that the failure to find a significant difference between normals and anxiety patients with MVP is a type Il error resulting from small sample size. For both CAs, the differences between groups were larger at night. This suggests that the groups differ in basal CA secretion rates and that daytime activity differences between the groups do not account for the findings. Data are not available to consider the possibility that the groups differed in activity levels or posture at night.

Patients in this study demonstrated substantial benefit from treatment with alprazolam or imipramine, but group sizes were too small to allow correlation of treatment response with pretreatment findings. The finding of decreased CA levcls during prolonged treatment is at variance with some reports (Ballenger et al., 1984), but is consistent with the observation that imipramine treatment causes a rise in plasma CAs that peaks at about 14 weeks of treatment and then declines toward baseline (Cameron et al., 1984). A study of CA levels in successfully treated panic-anxiety patients who are off medication would help to differentiate drug effects from changes associated with symptomatic improvement.

These results contradict the hypothesis that elevated CA levels in panic-anxiety patients are accounted for by the subgroup of patients with MVP, and suggest, instead, that the observed CA elevations result mainly from the subgroup of panic patients without MVP. If this difference in CA excretion between patients with MVP and without MVP is confirmed, it might provide an important clue to the existence and etiologies of two distinct subgroups of patients with panic. The number of subjects in this study is small, so no firm conclusion is yet justified, but studies of patients with panic attacks will need to consider the possibility that subgroups with and without MVP may differ on other variables, in addition to their rate of CA excretion.

\section{References}

American Psychiatric Association. DSM-III: Diagnostic and Statistical Manual of Mental Disorders. 3rd ed. APA, Washington, DC, p. 225 (1980).

Appleby, I.L., Klein, D.F., Sachar, E.J., and Levitt, M. Biochemical indices of lactateinduced panic: A preliminary report. In: Klein, D.F., and Rabkin, J.G., eds. Anxiety: New Research and Changing Concepts. Raven Press, New York, p. 411 (1981).

Ballenger, J.C., Peterson, G.A., Laraia, M., Hueck, A., Lake, C. R., Jimerson, D., Cox, D.J., Trockman, C., Shipe, J.R., Jr., and Wilkinson, C. A study of plasma catecholamines in agoraphobia and the relationship of serum tricyclic levels to treatment response. In: Ballenger, J.C., ed. Biology of Agoraphobia. American Psychiatric Press, Inc., Washington, DC, p. 42 (1984).

Boudoulas, H., Reynolds, J.C., Mazzaferri, F., and Wooley, C.F. Metabolic studies in mitral valve prolapse syndrome. Circulation. 61, 1200 (1980).

Boudoulas, H., Reynolds, J.C., Mazzaferri, E., and Wooley, C.F. Mitral valve prolapse syndrome: The effect of adrenergic stimulation. Journal of the American College of Cardiology, 2, 638 (1983).

Cameron, O.G., Smith, C.B., Hollingsworth, P.J., Nesse, R.M., and Curtis, G.C. Platelet alpha $_{2}$-adrenergic receptor binding and plasma catecholamines in panic anxiety before and during imipramine treatment. Archives of General Psychiatry 41, 1144 (1984).

Cannon, W. B. Bodily Changes in Pain, Hunger, Fear and Rage. Appleton, New York (1915).

Crowe, R.R., Pauls, D.L., Slyman, D.S., and Noyes, R. A family study of anxiety neurosis: Morbidity risk in families of patients with and without mitral valve prolapse. Archives of General Psvchiatry, 37, 77 (1980). 
DeCarvalho, J.G.R., Messerli, F.H., and Frolich, E.D. Mitral valve prolapse and borderline hypertension. Hypertension, 1, 518 (1979).

Frankenhauser, M. Behavior and circulating catecholamines. Brain Research, 31, 241 (1971).

Gaffney, F.A., Bastian, B.C., Lane, L.B., Taylor, W.F., Horton, J., Schutte, J.E., Graham, R.M., Pettinger, W., Blumquist, C.G., and Moore, W.E. Abnormal cardiovascular regulation in the mitral valve prolapse syndrome. American Journal of Cardiology, 52, 316 (1983).

Gilbert, B.W., Schatz, R.A., Von Raman, O.T., Behar, V.S., and Kissho, J. Mitral valve prolapse: Two dimensional echocardiography and angiography correlation. Circulation, 54, 716 (1976).

Ko, G.N., Elsworth, J.D., Roth, R.H., Rifkin, B.G., Leigh, H., and Redmond, E. Panicinduced elevation of plasma MHPG level in phobic-anxious patients. Archives of General Psychiatry, 40, 425 (1983).

Lader, M. The peripheral and central role of the catecholamines in the mechanisms of anxiety. International Pharmacopsychiatry, 9, 125 (1974).

Lader, M. Current psychophysiological theories of anxiety. In: Lipton, M.A., DiMascio, A., and Killam, K.F., eds. Psychopharmacology: A Generation of Progress. Raven Press, New York, p. 1375 (1978).

Liebowitz, M.R., Fyer, A.J., Appleby, I., Levitt, M., Gorman, J., Dillon, D., Levy, G., Anderson, S., Davies, S.O., Palij, M., and Klein, D.F. Lactate provocation of panic attacks. Psychopharmacology Bulletin, 19, (3), 476 (1983).

Markiewicz, W., Stoner, J., London, E., Hunt, S.A., and Popp, R.L. Mitral valve prolapse in one hundred presumably healthy young females. Circulation, 53, 464 (1976).

Mathew, R.J., Ho, B.T., Francis, D.J., Taylor, D.L., and Weinman, M.L. Catecholamines and anxiety. Acta Psychiatrica Scandinavica, 65, 142 (1982).

Mathew, R.J., Ho, B.T., Kralik, D., Semchuk, K., Weinman, M., and Claghorn, J.L. Catechol-O-methyltransferase and catecholamines in anxiety and relaxation. Psychiatry Research, 3, 85 (1980).

McCann, D.S., and Huber-Smith, M.J. Plasma catecholamines. Journal of Clinical Immunoassay, 6, 308 (1984).

Morganroth, J., Jones, R.H., Chen, C.C., and Naito, M. Two dimensional echocardiography in mitral, aortic and tricuspid prolapse: The clinical problem, cardiac nuclear imaging considerations and a proposed standard for diagnosis. American Journal of Cardiology, 46, 1164 (1980).

Nesse, R.M., Cameron, O.G., Curtis, G.C., McCann, D.S., and Huber-Smith, M.J. Adrenergic function in panic anxiety patients. Archives of General Psychiatry, 41, 771 (1984).

Nesse, R. M., Curtis, G.C., Thyer, B.A., McCann, D.S., Huber-Smith, M.J., and Knopf, R.F. Endocrine and cardiovascular responses during phobic anxiety. Psychosomatic Medicine (in press).

Pasternak, A., Tubau, J.F., Puddu, P.E., Krol, R.B., and DeChamplain, J. Increased plasma catecholamine levels in patients with symptomatic mitral valve prolapse. American Journal of Medicine, 73, 783 (1982).

Redmond, D.E., Jr. New and old evidence for the involvement of a brain norepinephrine system in anxiety. In: Fann, W.E., Karacan, I., Pokorny, A.D., and Williams, R.L. Phenomenology and Treatment of Anxiety. Spectrum Publications, New York (1979).

Rosenberg, C.A., Derman, G.H., Grabb, W.C., and Buda, A.J. Hypomastia and mitral valve prolapse. New England Journal of Medicine, 309, 1230 (1983).

Sheehan, D.V., Coleman, J.H.; Greenblatt, D.J., Jones, K.J., Levine, P.H., Orsulak, P.J., Peterson, M., Schildkraut, J.J., Uzogara, E., and Watkins, D. Some biochemical correlates of panic attacks with agoraphobia and their response to a new treatment. Journal of Clinical Psychopharmacology, 4, 66 (1984). 
Shulman, R., Griffiths, J., and Diewold, P. Catechol- $O$-methyltransferace activity in patients with depressive illness and anxiety states. British Journal of Psychiatry, 132, 133 (1978).

Uhde, T.W., Siever, L.J., Post, R.M., Jimerson, D.C., Boulenger, J., and Buchsbaum, M.S. The relationship of plasma-free MHPG to anxiety and psychophysical pain in normal volunteers. Psychopharmacology Bulletin, 18(4), 129 (1982).

Usdin, E., Kvetnansky, R., and Kopin, I.J., eds. Catecholamines and Stress: Recent Advances. Elsevier/North-Holland, New York (1980).

Ward, M.M., Mefford, I.N., Parker, S.D., Cheskey, M.A., Taylor, C.B., Keegan, D.L., and Barchas, J.D. Epinephrine and norepinephrine responses in continuously collected human plasma to a series of stressors. Psychosomatic Medicine, 45, 471 (1983).

Wyatt, R.J., Portnoy, B., Kupfer, D.J., Snyder, E., and Engelman, K. Resting plasma catecholamine levels in patients with depression and anxiety. Archives of General Psychiatry, 24, 65 (1971). 